\title{
ПОГРАНИЧНЫЕ КЕМБРО-ОРДОВИКСКИЕ ОТЛОЖЕНИЯ РАЗРЕЗА САКА II В СЕВЕРО-ВОСТОЧНОЙ ЭСТОНИИ
}

Литолого-минералогическая характеристика отложений стратотипического разреза раннуской пачки $\left(\epsilon_{3}-\mathrm{O}_{1} k l \mathrm{R}\right)$ каллавереской свиты разреза Сака II приведена в отдельной статье (Хейнсалу и др., 1991). Здесь излагаются результаты изучения органических остатков, представленных беззамковыми брахиоподами, граптолитами, конодонтами и акритархами.

Беззамковые брахиоподы в раннуской пачке, особенно в прослоях ракушечника или детритита, представлены в массовом количестве, но почти всегда сильно окатанными фрагментами створок плохой сохранности. В то время как в Западной Әстонии в отложениях маардуской пачки часто встречаются хорошо сохранившиеся экземпляры беззамковых брахиопод (Хейнсалу и др., 1987), в раннуской пачке они, как правило, представлены только детритом. Но среди детрита в прослоях ракушечника-детритита (см. слои 6 и 8 , рис. 1) все же присутствуют довольно крупные фрагменты (до $2 / 3$ или $3 / 4$ створки), по которым в пробе Sa-84-9 (слой 6) удалось определить Ungula ingrica (Eichwald) и Schmidtites celatus (Volb.), а в пробе Sa-84-7 (слой 8) - Ungula ingrica (определения И. Пуура).

Граптолиты в разрезе Сака II обнаружены только в орасояской пачке. B низах ее (проба Sa-84-4) найдена Rhabdinopora flabelliformis multithecata (определения Д. Кальо; Kaljo и др., 1986), а в средней части (проба Sa-84-2) - Rhabdinopora flabelliformis cf. rossica (рис. 1). Обе формы характерны для верхней части пакерортского горизонта.

Конодонты. Предварительные определения конодонтов В. Вийра разреза Сака II уже приводились (Kaljo и др., 1986).

$\mathrm{B}$ явно кембрийской части разреза (пробы Sa-83-10, Sa-83-11) обнаружены параконодонты, которые представлены видами: Westergaardodina cf. bicuspidata, Prooneotodus cf. gallatini, Furnishina sp. (рис. 1).

В низах каллавереской свиты (пробы Sa-84-8 и Sa-84-9) конодонты отсутствуют. Первые истинные конодонты обнаружены в пробе Sa-84-7 в виде обломков Cordylodus proavus. По внешней морфологии это типичный представитель вида, имеющий прямой, слабо наклонный зубец и глубокую базальную полость. Причем, как обычно для разрезов Северной Эстонии, встречаются экземпляры двух типов: типа proavus, без вторичных зубчиков базальной полости, и типа lindstromi, с вторичными зубчиками базальной полости. Сплющенный элемент представлен обломанными кусочками, но все же устанавливается высокая базальная полость, которая и определяет принадлежность к аппарату C. poavus.

Выше по разрезу (проба Sa-84-6) комплекс конодонтов становится разнообразнее: Cordylodus proavus, C. lindstromi, C. aff. drucei, C. sp. 1. Cordylodus proavus представлен морфой $\beta$ (рис. 2,56 ), типом $C$. lindstromi и экземплярами с передним «килем» (рис. 2, 57, 58). C. lindstromi имеет сравнительно высокую базальную полость, т. е. является нетипичной формой (рис. $2,59,60$ ). В то же время сплющенные экземпляры, 


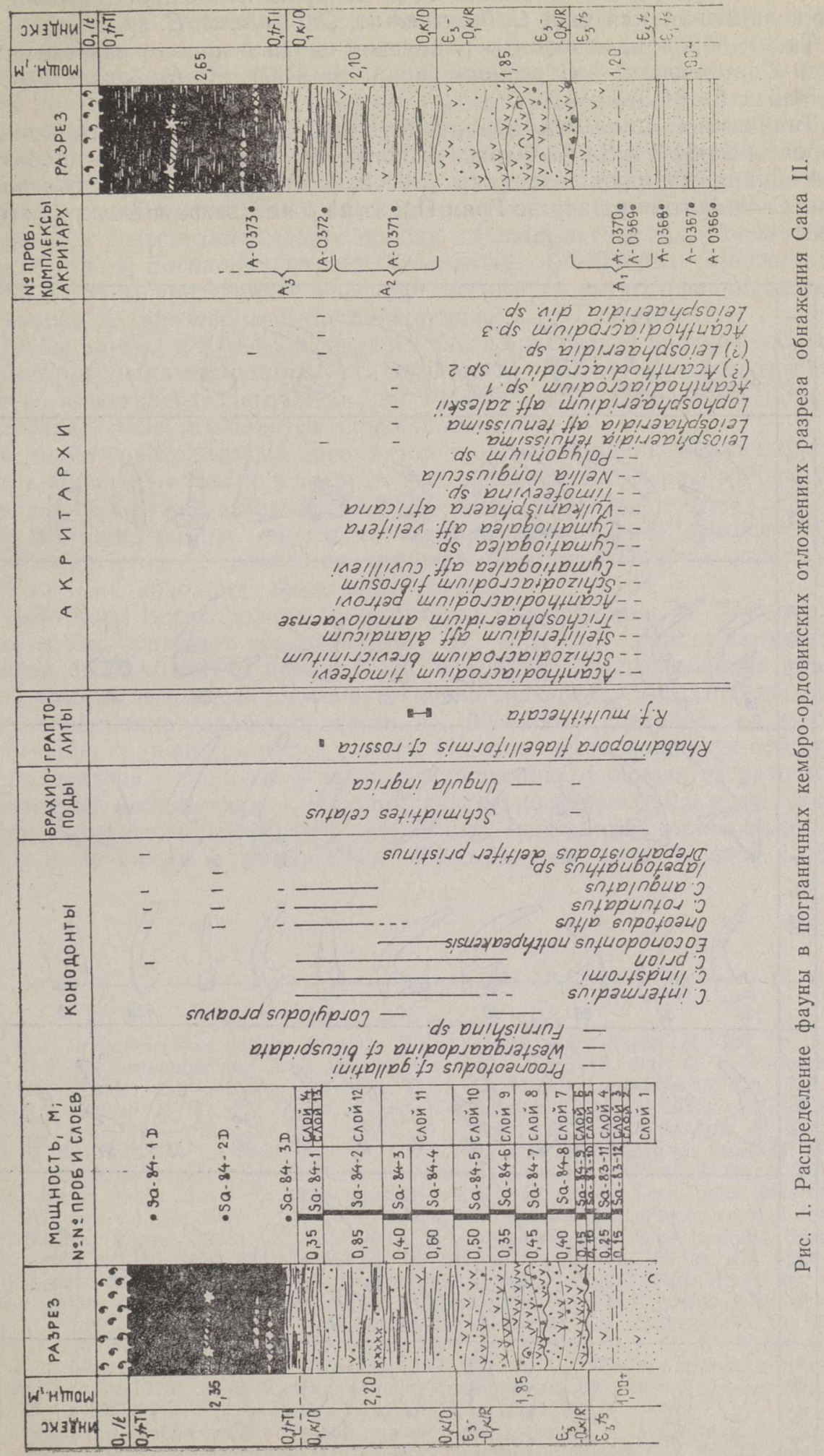


наоборот, имеют относительно низкую базальную полость (тип C. prion), чем подтверждают видовое определение C. lindstromi.

Аналогичный комплекс конодонтов обнаружен и в пробе Sa-84-5, но здесь прибавляются еще $C$. intermedius, $C$. viruanus, C. sp. 2.

Таким образом, конодонты раннуской пачки в данном разрезе относятся к двум зонам - C. proavus (проба Sa-84-7) и C. lindstromi (пробы Sa-84-6 и Sa-84-5).

Типичный $C$. lindstromi обнаружен в нижней части орасояской пачки в пробах Sa-84-3 и Sa-84-4 (рис. 2, 32, 33, 34). Кроме того, в пробе Sa84-4 обнаружен один экземпляр (рис. 2, 35), сходный с C. lindstromi из зоны C. lindstromi в разрезе Грин Пойнт на о-ве Ньюфаундленд (Barnes, 1988).

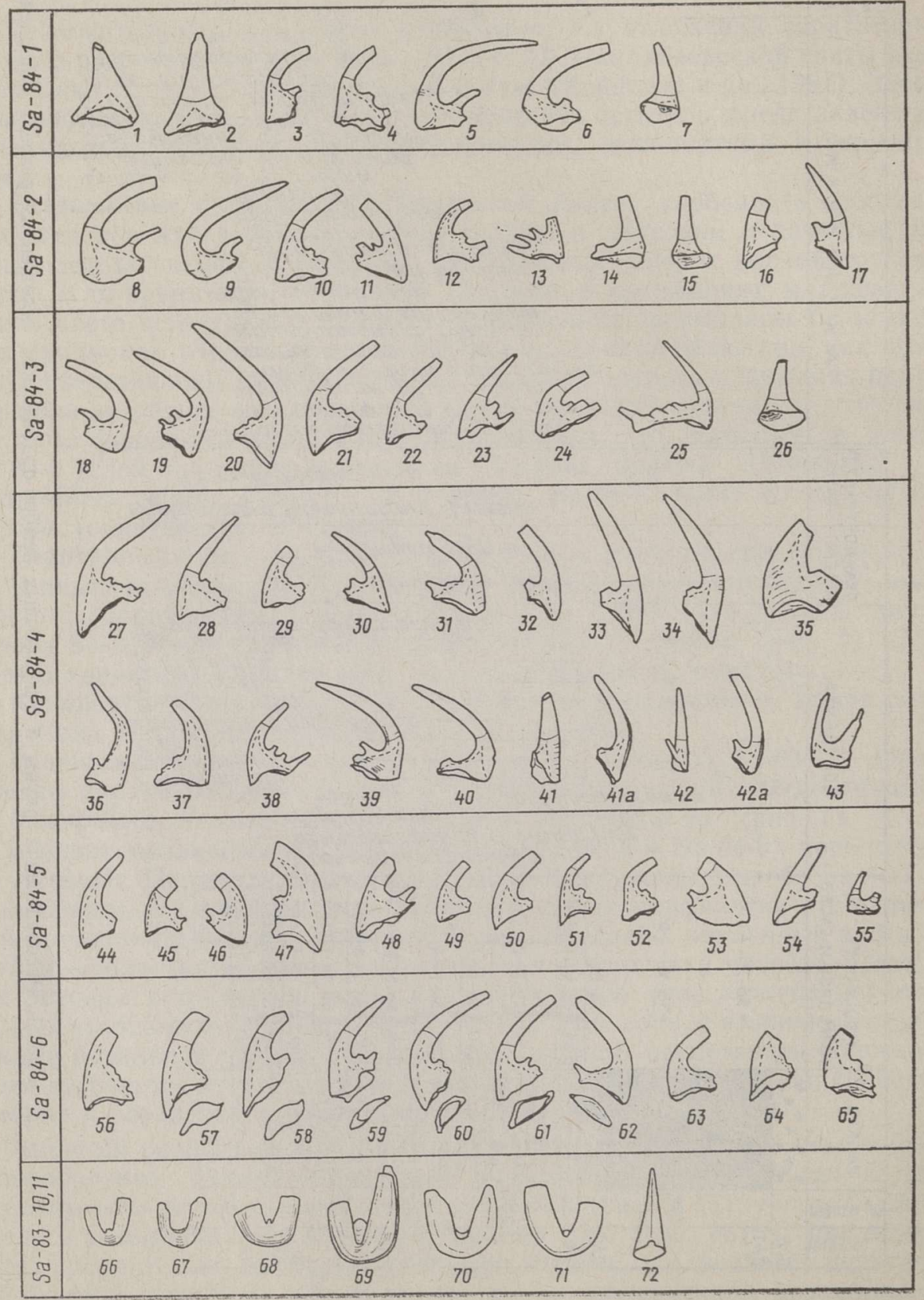


На границе раннуской и орасояской пачек (граница проб Sa-84-5 и Sa-84-4) наблюдается четкое изменение в комплексах конодонтов: появляются не только новые таксоны, но и изменяется морфология видов, переходящих из нижезалегающих слоев. Так, среди C. proavus, кроме уже известных, встречены экземпляры с очень высокой базальной полостью, характерные для ранней стадии эволюции C. proavus. C. lindstromi представлен типичной формой, хорошо сравнимой с экземплярами из разрезов Тоолсе, Турьекелдер и др. Выявленный в пробе Sa-84-4 Cordylodus sp. 1, многочисленный и характерный для данного уровня, включает экземпляры с базальной полостью, переходящие как в C. caboti, так и в $C$. intermedius (рис. $2,27,31$ ). Здесь появляются и продолжают встречаться в вышезалегающих пробах Iapetognathus sp., Cordylodus sp. 3, C. sp. 4, Eoconodontus notchpeakensis. Cordylodus intermedius (проба Sa-84-4) представлен морфологическим типом, отличающимся от зонального $C$. intermedius и приближающимся к C. angulatus.

Пробы Sa-84-1 и Sa-84-2 из верхней части орасояской пачки относятся к зоне Cordylodus rotundatus - C. angulatus. Многие виды переходят сюда из нижезалегающего слоя, но прибавляются зональные виды и E. notchpeakensis замещается Oneotodus altus.

В толще граптолитовых аргиллитов тоолсеской пачки удалось обнаружить конодонты только в алевритовых прослоях. Более разнообразный комплекс обнаружен в пробах Sa-84-2D и Sa-84-1D, где вид Drepanoistodus deltifer pristinus определяет зону pristinus. Кроме уже встреченных C. angulatus, C. rotundatus, Iapetognathus sp. и $O$. altus, определен конусовидный конодонт Acontiodus viirae.

Акритархи. Исследования на акритархи проводились И. Паалитсом годом позже основных исследований. За этот год стенки изученной траншеи были обтянуты проволочной сеткой для предотвращения обвалов, в том числе и место изучения основного разреза Сака II. В связи с этим опробование удалось провести на 100-200 м севернее, на месте пересечения траншеи с линией глинта. На этом месте мощности отложений орасояской и раннуской пачек по сравнению с основным разрезом практически не изменились. Но приблизительно вдвое (с 0,6 м до 1,3 м) возросла мощность отложений, залегающих между явно нижнекембрийскими тискрескими и раннускими отложениями (рис. 1, слои 2-5).

Рис. 2. Конодонты в разрезе Сака II.

Фиг. 1, 2. Drepanoistodus deltifer pristinus Viira, номера экземпляров Cn 1310, Cn 1311. Фиг. 3-5, 8. Cordylodus angulatus Pander, $\mathrm{Cn} 1312-\mathrm{Cn} 1315$. Фиг. 6, 9. Cordylodus rotundatus Pander, Cn 1316, Cn 1317. Фиг. 7, 14, 15, 26. Iapetognathus sp., Cn $1318-$ Cn 1321. Фиг. 10, 11, 21, 22, 27-31, 61, 62. Cordylodus sp. 1, Cn $1322-\mathrm{Cn} 1332$. Фиг. 12, 13, 51, 52. Cordylodus sp. 2, Cn 1333 - Cn 1336. Фиг. 16, 17, 41, 42. Cordylodus sp. 3, Cn 1337 - Cn 1340. Фиг. 18. Cordylodus intermedius ssp. 1, Сn 1341. Фиг. 19, 20. Cordylodus caboti Bagnoli, Barnes et Stevens?, Cn 1342, Cn 1343. Фиг. 23-25. Cordylodus sp. 4, Cn 1344 - Cn 1346. Фиг. 32-34, 48-50, 59, 60. Cordylodus lindstromi Druce et Jones s. 1., Cn $1347-$ Cn 1354. Фиг. 35. Cordylodus lindstromi Druce et Jones sensu Barnes (Barnes, 1988), Cп 1355. Фиг. 36. Cordylodus primitious Bagnoli, Barnes et Stevens, Cn 1356. Фиг. 37, 45-47, 57, 58. Cordylodus proavus Müller, Cn $1357-$ Cn 1362. Фиг. 38, 44, 56. Cordylodus proavus beta morph, Cn 1363 - Cn 1365. Фиг. 39, 53. Cordylodus intermedius ssp. 2, Cn 1366, Cn 1381. Фиг. 40, 63. Cordylodus aff. drucei Miller, Cn 1367, Cn 1368. Фиг. 43, 55. Cordylodus viruanus Viira et Sergeyeva, Cn 1369, Cn 1370. Фиг. 54, 64, 65. Cordylodus sp., Cn $1371-\mathrm{Cn} 1373$. Фиг. 66, 67. Westergaardodina cf. bicuspidata Miller, Cn 1374, Cn 1375. Фиг. 70, 71. Westergaardodina bicuspidata Müller, Cn 1376, Cn 1377. Фиг. 68, 69. Westergaardodina moessebergensis Müller, Cn 1378, Cn 1379. Фиг. 72. Furnishina furnishi Müller, Cn 1380.

Все экземпляры изображены с боковой стороны, кроме фиг. $7,14,15,26,41 a, 42 a$, которые зарисованы с задней стороны. Увеличение одинаковое, кроме $1,2,35,43$, которые примерно в два раза больше. 
Здесь в двух глинистых прослоях (пробы А-0369 и А-0370) обнаружен следующий комплекс акритарх: Acanthodiacrodium timofeevii Gol. et Volk., Schizodiacrodium brevicrinitum Gol. et Volk., Stelliferidium aff. alandicum Tynni, Trichosphaeridium annolovaense Timof., Acanthodiacrodium petrovi Timof., Schizodiacrodium fibrosum Gol. et Volk., Cymatiogalea aff. cuvillievi Durnff., Cymatiogalea sp., Cymatiogalea aff. velifera Durnff., Vulcanisphaera africana Durnff., Timofeevia sp., Nellia longiuscula Gol. et Volk., Polygonium sp. Этот комплекс акритарх является характерным для нижней части ладожской свиты верхнего кембрия и описан в обнажении р. Ижора Ленинградской области (Волкова, Голуб, 1985).

Отложения раннуской пачки на акритархи не опробованы, поскольку в них не оказалось перспективных глинистых прослоев, к которым акритархи всегда приурочены.

Орасояская пачка охарактеризована двумя пробами акритарх. Отличительной особенностью комплексов акритарх, представленных в них, является обильная встречаемость экземпляров при относительной бедности их видового состава.

В нижней половине пачки (проба А-0371, соответствует пробе Sa-84-3; рис. 1, слой 11) обнаружен следующий комплекс акритарх: Leiosphaeridia tenuissima Eisenack, Leiosphaeridia aff. tenuissima, Lophosphaeridium aff. zaleskii, Acanthodiacrodium sp. 1, (?) Acanthodiacrodium sp. 2. В особенно массовом количестве представлены два первых из них. Leiosphaeridia tenuissima Eisenack и Lophosphaeridium aff. zaleskii впервые описаны А. Эйзенаком в граптолитовых аргиллитах Ленинградской области (Eisenack, 1958), т. е. их можно считать характерными для верхней части пакерортского горизонта. Однако эти оба вида имеют довольно широкий диапазон вертикального распространения, что сужает возможности использования их в детальной стратиграфии. Более ценными в этом смысле могут оказаться Acanthodiacrodium sp. 1 и (?) Acanthodiacrodium sp. 2, которые при нынешней степени изученности пока не могут быть определены до вида. По всей вероятности, это новые, неизвестные до сих пор виды.

В верхней половине орасояской пачки (проба А-0372, ориентировочно соответствует пробе Sa-84-2; рис. 1 , слой 12 основного разреза) количество видов акритарх заметно сокращается. Их комплекс представлен следующими видами: Leiosphaeridia aff. tenuissima, (?) Leiosphaeridia sp., Acanthodiacrodium sp. 3, Leiosphaeridia div. sp. По-видимому, в виде (?) Leiosphaeridia sp. и Acanthodiacrodium sp. 3 мы имеем дело с новыми видами, появление которых обозначает определенную смену комплексов акритарх уже в орасояской пачке. Напомним, что четкое изменение комплексов конодонтов в рассматриваемом разрезе также происходило на нижней границе орасояской пачки, т. е. внутри зоны Cordylodus lindstromi.

В низах тоолсеской пачки (проба А-0373) количество видов акритарх сокращается до минимума: в массовом количестве представлен только (?) Leiosphaeridia sp., который переходит сюда из верхней половины орасояской пачки.

Таким образом, в изученном разрезе можно выделить три комплекса акритарх: A-1 характеризует отложения нижней части ладожской (т. е. тситреской) свиты верхнего кембрия, непосредственно подстилающие раннуские отложения; A-2 - отложения нижней половины орасояской пачки, непосредственно перекрывающие раннуские отложения, и А-3 верхи орасояской-низы тоолсеской пачек. В нижнем комплексе при массовой встречаемости акритарх наблюдается богатый и разнообразный видовой состав их. Выше по разрезу, с возрастанием доли прослоев граптолитовых аргиллитов в отложениях каллавереской свиты, значительно 
сокращается количество видов, доходя в низах вышезалегающей толщи граптолитовых аргиллитов тюрисалуской свиты до одного единственного вида, который, однако, встречается в массовом количестве. Такое явление, видимо, указывает на экстремальность условий существования акритарх в богатой органикой среде. С другой стороны, исследования, проведенные для выяснения закономерностей распространения и фациальной приуроченности их, выявили массовую встречаемость акритарх типа Leiosphaeridia в очень мелководных осадках (Staplin, 1961; Smith, Saunders, 1970). A Leiosphaeridia в данном случае преобладает в отложениях как орасояской, так и тоолсеской пачек.

Таким образом, из всего комплекса органических остатков в разрезе Сака II только конодонты позволяют проводить внутреннее биостратиграфическое расчленение как раннуской пачки, так и каллавереской свиты в целом. В раннуской пачке, начиная с верхнего циклита (рис. 1, слои 8-10), установлены две конодонтовые зоны: Cordylodus proavus (слой 8) и C. lindstromi (слои 9,10$)$. Последняя зона продолжается в нижней половине орасояской пачки (слой 11). Верхняя половина орасояской пачки (слои 12-14) относится уже к зоне C. rotundatusC. angulatus, которая охватывает и большую часть тоолсеской пачки $\left(\mathrm{O}_{1} t r \mathrm{Tl}\right)$, а верхи ее представлены зоной Drepanoistodus deltifer pristinus (проба Sa-84-1D).

В нижнем циклите раннуской пачки (слои 6,7$)$ конодонты не обнаружены. Следовательно, возраст низов раннуской пачки может быть определен только косвенно по возрасту подстилающих и перекрывающих отложений. В подстилающих раннускую пачку отложениях обнаружен комплекс акритарх, характерный для нижней части ладожской свиты верхнего кембрия $\left(E_{3} l d\right)$, что в комплексе с литологической характеристикой этих отложений (слои $2-5$ ) позволяет отнести их к тситреской свите $\left(\epsilon_{3} t s\right)$, впервые выделенной в разрезе Турьекелдер Западной Эстонии (Попов, Хазанович, 1985).

Итак, низы раннуской пачки не древнее верхов зоны Westergaardodina (верхов подзоны Proconodontus) и не моложе зоны Cordylodus proavus, т. е. по возрасту нижний циклит раннуской пачки может быть отнесен к верхам зоны Westergaardodina, к зоне Cordylodus andresi или к низам зоны C. proavus, или ко всем вместе (Kaljo и др., 1986).

До окончательного решения вопроса о проведении границы кембрияордовика в международном масштабе в Советском Союзе пока принято проводить ее по конодонтам в основании зоны Cordylodus proavus. Следовательно, в разрезе Сака II она совпадает с началом верхнего циклита (подошва слоя 8), который со следами размыва залегает на нижнем. Таким образом, граница кембрия-ордовика здесь проходит внутри раннуской пачки, а в Западной Эстонии она располагается внутри маардуской пачки в ее стратотипическом разрезе Юлгазе.

Следует еще обратить внимание на положение зоны C. rotundatusC. angulatus в разрезе. Эта зона, как наиболее выдержанная по всему глинту в изучаемом комплексе тремадокских отложений, служит хорошим корреляционным уровнем. В разрезе Сака II основание этой зоны расположено в середине орасояской пачки. К западу, в районе ВихулаТоолсе, оно находится в нижней части кателаской пачки, а в Западной Эстонии совпадает с нижней границей суурйыгиской пачки (Kaljo и др., 1986; Хейнсалу и др., 1987; Kaljo и др., 1988; Mens и др., 1989). Это является хорошим примером сечения литостратиграфических единиц временными границами биозон. Қак показывает опыт изучения, границы биозон в тремадокских отложениях Северной Эстонии не имеют литологического контроля и могут устанавливаться в каждом конкретном разрезе только путем очень трудоемкого изучения конодонтов. Отсюда очевидна необходимость выделения литостратиграфических единиц в этой очень 
сложной и изменчивой толще, характеризующейся прерывистостью осадконакопления, но очень часто без видимых следов перерывов. Другого мнения придерживаются наши ленинградские коллеги Л. Е. Попов и K. К. Хазанович, которые в своей альтернативной схеме расчленяют тремадокские отложения Әстонии на свиты (циклы) и пачки в первую очередь по фаунистическим критериям (Опорные разрезы ..., 1989). В свете этого хочется обратить внимание на спорность выделения в этой схеме цикла под названием лахемааской свиты, нижняя граница которой в Западной Эстонии совпадает с основанием зоны $C$. rotundatus-C. angulatus (нижняя граница суурйыгиской пачки), а в разрезе Сака II «опускается» до основания зоны $C$. proavus, т. е. до границы кембрия-ордовика.

Многолетняя практика изучения тремадокских отложений Эстонии показала, что целесообразно выделять в них в первую очередь литостратиграфические единицы (свиты и пачки), точно привязывая к ним фаунистическую характеристику. Разработка биозональной шкалы должна проводиться независимо от ранее выделенных литоединиц.

\section{Л ИТЕ Р АТ У Р А}

Волкова Н. А., Голуб И. Н. Новые акритархи верхнего кембрия Ленинградской области (Ладожская свита). - Палеонтол. ж., 1985, № 4, 90-98.

Опорные разрезы и стратиграфия кембро-ордовикской фосфоритоносной оболовой толщи на северо-западе Русской платформы. Л., 1989.

Попов Л. Е., Хазанович $K$. K. Новые данные по стратиграфии кембро-ордовикских фосфоритоносных отложений на северо-западе Русской плиты. - Тр. ГИГХС, 1985, вып. 63, 38-47.

Хейнсалу Х., Вийра В., Менс K., Оя $T$., Пуура Н. Кембрийско-ордовикские пограничные отложения разреза Юлгазе, Северная Эстония (неостратотип маардуской пачки). - Изв. АН ЭССР. Геол., 1987, 36, № 4, 154-165.

Хейнсалу X., Курвитс $T$., Оя $T$. Литолого-минералогическая характеристика стратотипического разреза раннуской пачки $\left(\mathrm{E}_{3}-\mathrm{O}_{1} k l \mathrm{R}\right)$ в Сака II, Северо-Восточная Эcтония. - Изв. АН Эстонии. Геол., 1991, 40, № 1, 1-7.

Barnes, $C$. $R$. The proposed Cambrian-Ordovician global boundary stratotype and point (GSSP) in Western Newfoundland, Canada. - Geol. Mag., 1988, 125, N 4, 381414.

Eisenack, A. Mikrofossilien aus dem Ordovizium des Baltikums. - Senck. leth., 1958, 39 , N 5/6, 389-405.

Kaljo, D., Borovko, N., Heinsalu, H., Khazanovich, K., Mens, K., Popov, L., Sergeyeva, S., Sobolevskaya, R., Viira, V. The Cambrian-Ordovician boundary in the BalticLadoga clint area (North Estonia and Leningrad Region, USSR). - Proc. Acad. Sci. ESSR. Geol., 1986, 35, N 3, 97-108.

Kaljo, D., Heinsalu, H., Mens, K., Puura, I., Viira, V. Cambrian-Ordovician boundary beds at Tõnismägi, Tallinn, North Estonia. - Geol. Mag., 1988, 125, N 4, 457463.

Mens, K., Viira, V., Paalits, I., Puura, I. Cambrian-Ordovician boundary beds at Mäekalda, Tallinn, North Estonia. - Proc. Acad. Sci. ESSR. Geol., 1989, 38, N 3, $101-111$.

Smith, N.D., Saunders, R. S. Paleoenvironments and their control of acritarch distribution Silurian of east-central Pennsylvania. - J. Sed. Petrol., 1970, 40, N 1, $324-333$.

Staplin, P. L. Reef-controlled distribution of Devonian microplankton in Alberta. Paleontology, 1961, 4, part 3, 392-424.

Институт геологии

Академии наук Әстонии

тартуский университет
Поступнла в редакцию $14 / \mathrm{V} 1990$ 


\section{KAMBRIUMI JA ORDOVIITSIUMI PIIRIKIHID KIRDE-EESTI SAKA II LÄBILÕIKES}

Piirikihtides on esindatud Tsitre $\left(\Theta_{3} t s\right)$ ja Kallavere $\left(\Theta_{3}-\mathrm{O}_{1} k l\right)$ kihistu, viimane omakorda jaguneb Rannu (R) ja Orasoja (O) kihistikuks. Rannu kihistik koosneb kahest tsükliidist, mis mõlemad algavad brahhiopoodide fragmentide kuhjega eriteralise suhteliselt jämeda kvartsliiva(kivi) sees, nn. ooboluskonglomeraadiga. Kambriumi ja ordoviitsiumi piir, mille kriteeriumiks on konodondi Cordylodus proavus esmane ilmumine läbilõikes, asub Rannu kihistiku sees (kiht 8 all, joon. 1), langedes kokku ülemise tsükliidi alumise piiriga. Alumises tsükliidis (kihid 6-7) aga ei ole leitud konodonte, praegu veel ainsat faunaliiki, mis võimaldab Kallavere kihistu sisemist liigestamist. Seega alumise tsükliidi biotsonaalse kuuluvuse maksimaalsed võimalikud piirid on määratavad ainult kaudselt, lamami ja lasumi kaudu ning jäävad intervalli: osa Cordylodus proavus'e tsoonist, C. andresi tsoon ja osa Westergaardodina tsoonist (Proconodontus'e alamtsooni ülemine osa; vt. Kaljo jt., 1986). Vōimalik, et Rannu kihistiku (ühtlasi ka Kallavere kihistu) alumises osas esineb ainult üks või ainult osa ühest ülaltoodud kolmest konodonditsoonist.

Alates Rannu kihistiku ülemisest tsükliidist on Saka II paljandi Tremadoci kivimites välja eraldatud järgmised konodonditsoonid: Cordylodus proavus (kiht 8), C. lindstromi (kihid 9-11), C. rotundatus - C. angulatus (kihid $12-14$ ja valdav osa Toolse $\left(\mathrm{O}_{1} \operatorname{tr} \mathrm{Tl}\right.$ ) kihistikust) ja Drepanoistodus deltifer pristinus (Toolse kihistiku ülemine osa, proov Sa-84-1D, joon. 1).

\section{Heljo HEINSALU, Viive VIIRA and Ivo PAALITS}

\section{CAMBRIAN-ORDOVICIAN BOUNDARY BEDS IN THE SAKA II SECTION, NORTH-EAST ESTONIA}

In the studied boundary beds the Tsitre $\left(E_{3} t s\right)$ and Kallavere $\left(E_{3}-\mathrm{O}_{1} k l\right)$ Formations are represented; the latter is, in turn, subdivided into the Rannu (R) and Orasoja (O) Members. The Rannu Member consists of two cycles. Both cycles start with the accumulation of brachiopod fragments in varigrained relatively coarse quartzose sandstone, the so-called Obolus conglomerate. The Cambrian-Ordovician boundary, defined by the first appearance of the conodont Cordylodus proavus in the section, lies within the Rannu Member (below bed 8, Fig. 1) and corresponds to the lower boundary of its upper cycle. Subdivision of the Kallavere Formation is possible only by conodonts, but they were not found in the lower cycle (beds 6-7) of the Rannu Member. Therefore, the biostratigraphical boundaries of the lower cycle can be determined only roughly by conodonts of the under- and overlying beds. The biostratigraphic interval corresponding to the lower cycle of the Rannu Member can include maximally part of the Cordylodus proavus Zone, the $C$. andresi Zone, and the upper part of the Westergaardodina Zone (Proconodontus Subzone; Kaljo et al., 1986). However, this interval can comprise only one of these zones, or only part of one zone.

Four conodont zones were established in section Saka II of the Kallavere and Türisalu Formations: Cordylodus proavus (bed 8), C. lindstromi (beds 9-11), C. rotundatus-C. angulatus (beds 12-14 and the lower part of higher Dictyonema shale of the Toolse Member - $\mathrm{O}_{1} t r \mathrm{Tl}$, samples Sa-84-3D and Sa-84-2D, Fig. 1), and the Drepanoistodus deltifer pristinus Zone (sample Sa-84-1D). 